
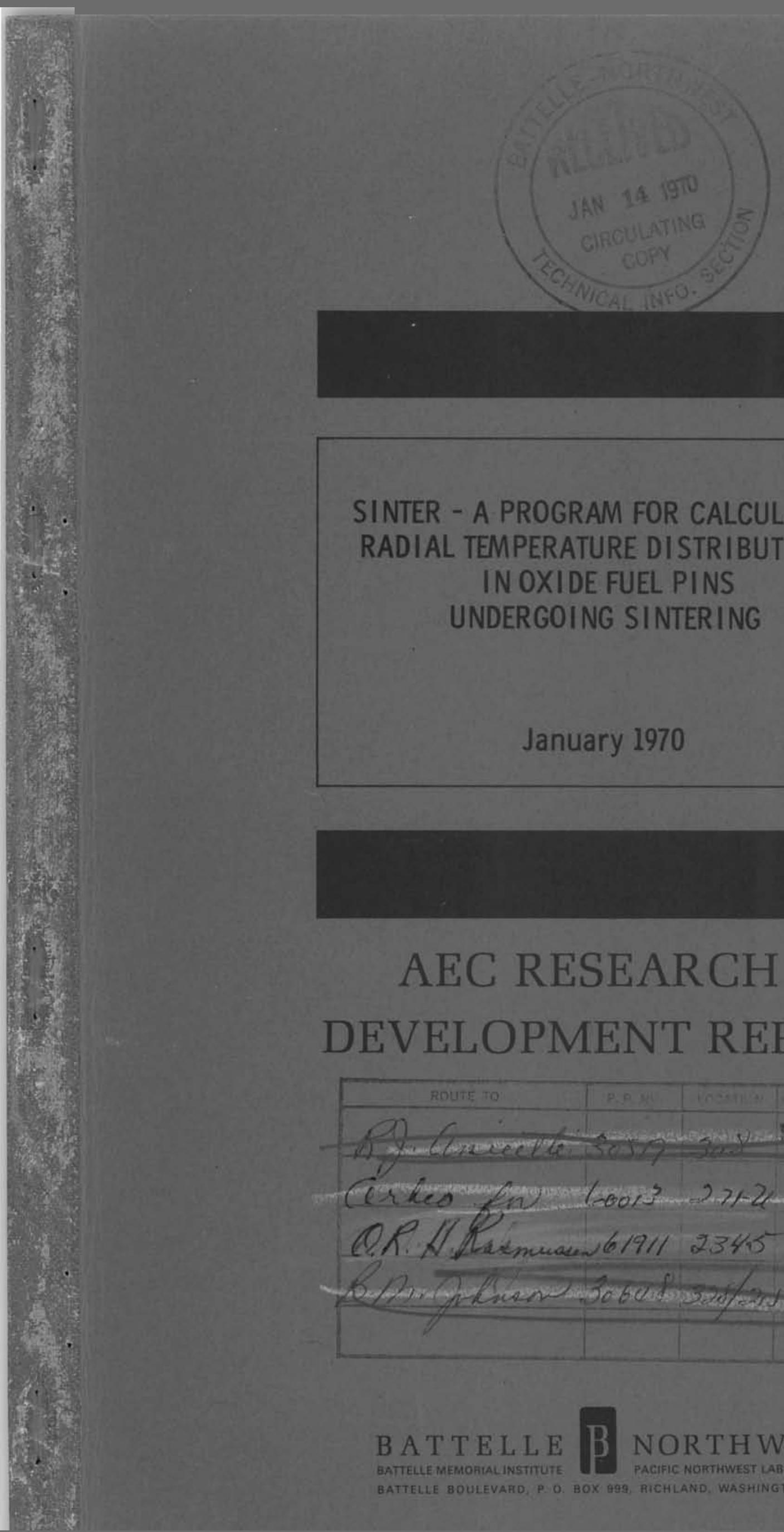

BNWL-1241

UC-80

$1-70$

\title{
SINTER - A PROGRAM FOR CALCULATING RADIAL TEMPERATURE DISTRIBUTIONS IN OXIDE FUEL PINS UNDERGOING SINTERING
}

January 1970

\section{AEC RESEARCH \& DEVELOPMENT REPORT}

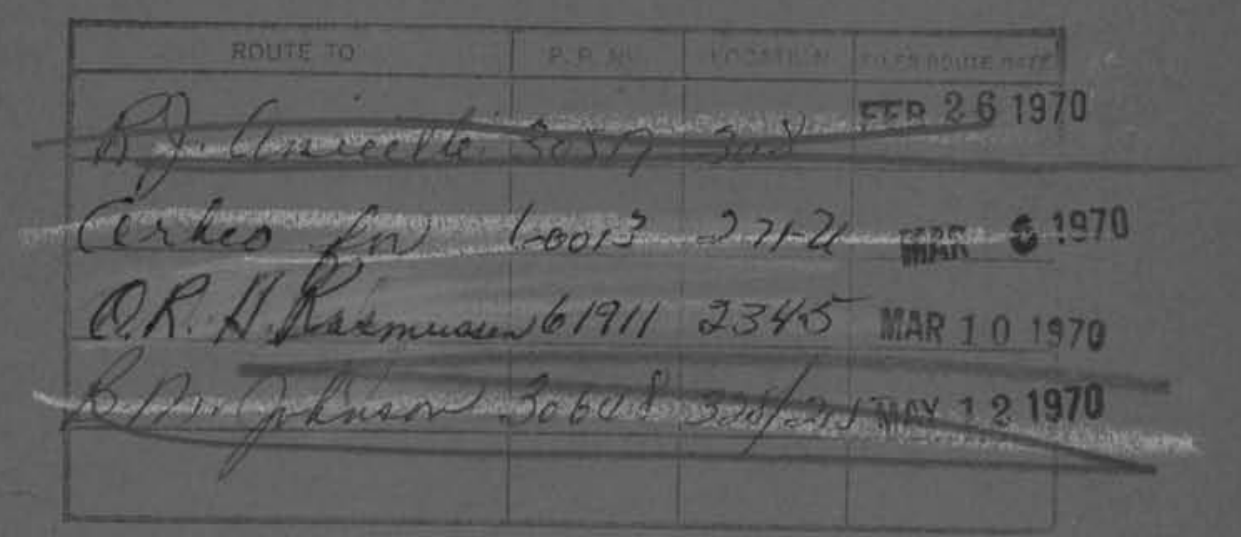

B A T TELLE B NORTHWEST BATTELLE MEMORIALINSTITUTE EACIFIC NORTHWEST LABORATORIES BATTELLE 8OULEVAFD, P. O. BOX G99, RICHLAND, WASHINGTON 9935: 


\section{LEGAL NOTICE}

This report was prepared as an account of Government sponsored work. Neither the United States, nor the Commission, nor any person acting on behalf of the Commission:

A. Makes any warranty or representation; expressed or implied, with respect to the accuracy, completeness, or usefulness of the information contained in this report, or that the use of any information, apparatus, method, or process disclosed in this report may not infringe privately owned rights; or

B. Assumes any liabilities with respect to the use of, or for damages resulting from the use of any information, apparatus, method, or process disclosed in this report.

As used in the above, "person acting on behalf of the Commission" includes any employee or contractor of the Commission, or employee of such contractor, to the extent that such employee or contractor of the Commission, or employee of such contractor prepares, disseminates, or provides access to, any information pursuant to his employment or confract with the Commission, or his employment with such confractor.

\section{PACIFIC NORTHWEST LABORATORY}

RICHLAND, WASHINGTON

operated by

BATTELLE MEMORIAL. INSTITUTE

for the

UNITED STATES ATOMIC ENERGY COMMISSION UNDER CONTRACT AT(45-1)-1830 
BNWL -1241

UC- 80 , Reactor

Technology

\title{
SINTER - A PROGRAM FOR CALCULATING RADIAL TEMPERATURE \\ DISTRIBUTIONS IN OXIDE FUEL PINS UNDERGOING SINTERING \\ by
}

K. R. Merckx

Metallurgy and Ceramics Department

Chemistry and Metallurgy Division

\author{
and \\ G. I. $F \circ x$ \\ Reactor and Plant Technology Department \\ FFTF Division
}

\author{
January 1970
}

BATTELLE MEMORIAL INSTITUTE

PACIFIC NORTHWEST LABORATORIES

RICHLAND, WASHINGTON 99352 
BNWL- 1241

Printed in the United States of America Available from

Clearinghouse for Federal Scientific and Technical Information National Bureau of Standards, U.S. Department of Commerce Springfield, Virginia 22151

Price: Printed Copy $\$ 3.00 ;$ Microfiche $\$ 0.65$ 
BNWL- 1241

\title{
SINTER - A PROGRAM FOR CALCULATING RADIAL TEMPERATURE DISTRIBUTIONS IN OXIDE FUEL PINS UNDERGOING SINTERING
}

\author{
K. R. Merckx and G. L. Fox
}

\begin{abstract}
SINTER is a program for calculating the steady state radial temperature distribution within the fuel material of cylindrical fuel rods. The method uses the integral of the thermal conductivity over the temperature range which includes the temperature dependence for thermal conductivity. The fuel temperature distribution includes the effect of restructuring or sintering of the fuel material. The radius of the central void caused by such sintering is also calculated. This report reviews the theoretical basis of the procedure for calculating the temperature distributions and the geometrical changes.
\end{abstract}




\section{CONTENTS}

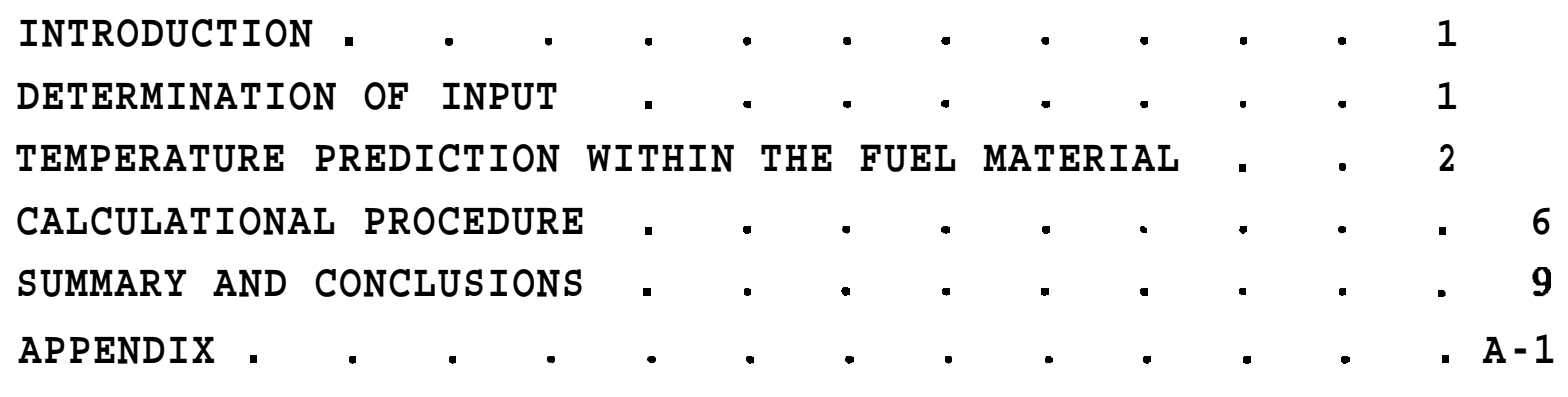


BNWL - 1241

\title{
SINTER - A PROGRAM FOR CALCULATING RADIAL TEMPERATURE
}

\section{$D$ I STR I BUT IONS IN OX DE FUEL PINS UNDERGO ING SINTER ING}

\author{
K. R. Merckx and G. L. Fox
}

\section{INTRODUCTION}

SINTER is a program for calculating the radial temperature distribution within the fuel material of cylindrical fuel rods. This program takes into account the temperature dependence of the thermal conductivity and changes in density produced by the restructuring or sintering of the fuel material. The radius of the central void caused by such sintering is also calculated. The calculations described here were used as the basis for a previously completed but undocumented program called SINTR that calculated the effect of sintering along a fuel pin. SINTR employed at each axial node location the techniques described herein. This report reviews the theoretical basis of the procedure for calculating the temperature distributions and the geometrical changes.

\section{DETERMINATION OF INPUT}

The temperature calculations for the fuel material are based upon a description of the coolant flow conditions, the power generation within the fuel, and the initial geometry of the cladding and fuel material. The axial distribution of the power generation for SINTR is described by a chopped cosine curve where an extrapolation distance and the maximum power generation are used to describe this distribution. The coolant inlet temperature, mass flow rate, specific heat, and the prescribed power distribution are used to describe the coolant temperature condition at any axial location along the fuel pin. The temperature drops across the coolant film, the cladding, and the fuel gap interface are determined from the local linear heat generation rate and from the input values for the coolant film, gap conductances, and the thermal conductivity of the 
cladding. The fuel surface temperature is determined by adding these temperature drops to the local coolant temperature.

The SINTER program applies a one-dimensional heat conduction theory-for the radial temperature distribution within the fuel material. The integral of the themal conductivity over temperature as a function of the fraction of theoretical density* is given by:

$$
\begin{aligned}
& T \leq 3272 \\
& \mathrm{~S}(\mathrm{~T})=\frac{\mathrm{T}^{0.613}}{(0.09084-0.07306 \times \mathrm{D})} \cdot \frac{(54.615 \times \mathrm{D}+167.173)}{\exp (0.00154 \times \mathrm{T})} \\
& \mathrm{T}>3272 \\
& \mathrm{~S}(\mathrm{~T})=\mathrm{S}(3272)+1.31769 \times(\mathrm{T}-3272)
\end{aligned}
$$

where $S=$ Integrated thermal conductivity $[B t u /(h r \times f t)]$

$$
\begin{aligned}
& \mathrm{T}=\text { Tempeiature }\left({ }^{\circ} \mathrm{F}\right) \\
& \mathrm{D}=\text { Fraction of theoretical density. }
\end{aligned}
$$

This equation applies for a material of constant density and should be used to calculate the changes in the integral value of the thermal conductivity from a reference temperature, The fraction of theoretical density befsre and after sintering are prescribed by the input. The temperature at which sintering occurs is also prescribed by the input. The geometry of the fuel material is described by its initial inner and outer radius (Figure 1).

\section{TEMPERATURE PREDICTION WITHIN THE FUEL MATERIAL}

The temperatures within the fuel material are assumed to be described by the heat conduction equation in terms of cylindrical coordinates. Axial symmetry and radial flow of the heat

* T. J. Bennett, "Incorporation of the Revised Thermal Conductivity and Integral KdT Curves into the FFTF Fuel. Design Sintering Coder Internal PNL Letter, May 4, 2968. 
BNWL - 1241

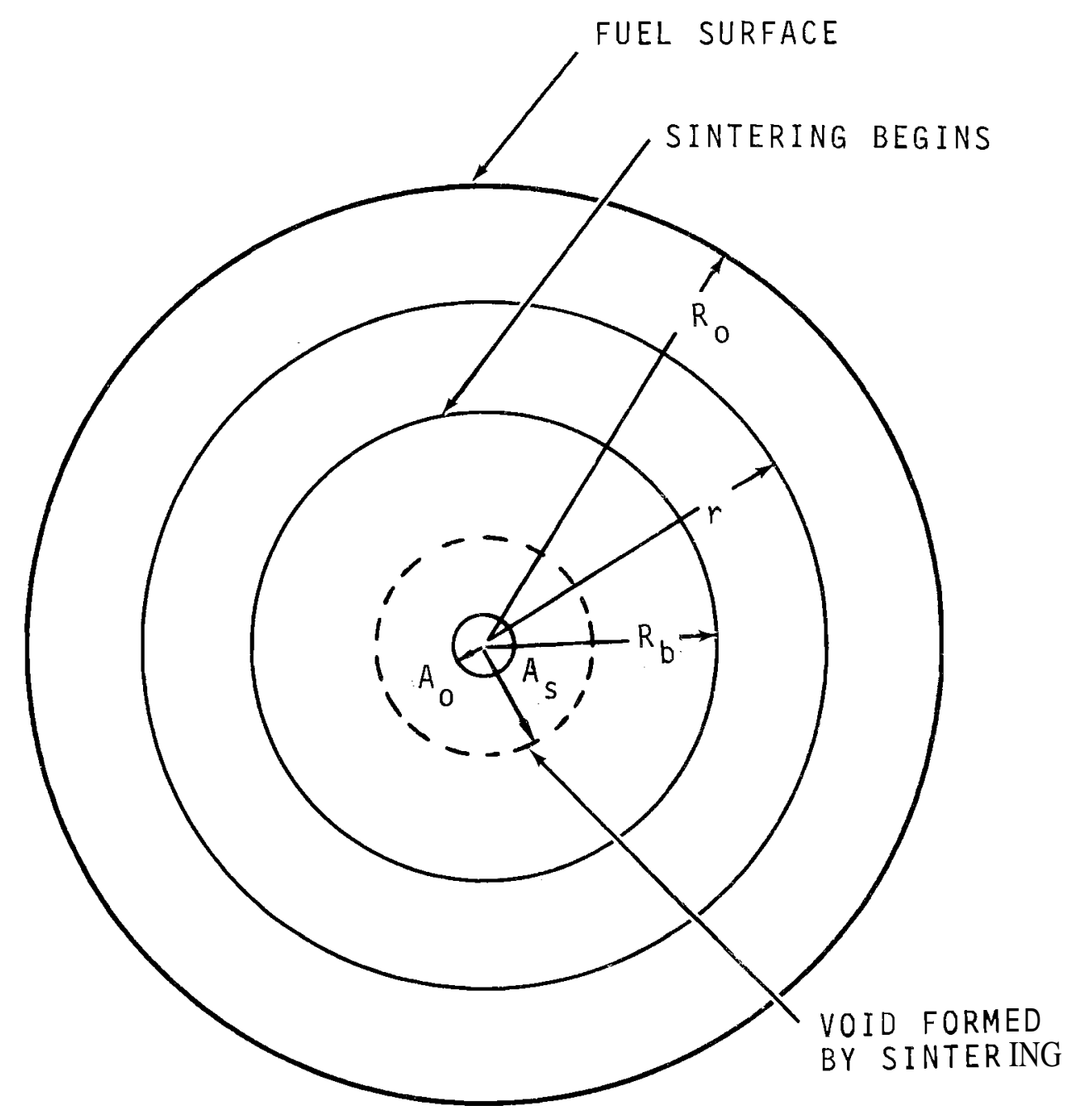

FIGURE 1. Schematic of Fuel Cross Section 
are assumed. The resultant equation for the temperature distribution, $T$, as a function of heat generation is

- $\left[\frac{1}{r} \frac{d}{d r} r\left(K \frac{d T}{d r}\right)\right]=q(r)$, where

$q$ is the volumetric heat generation, and

$K=$ the temperature dependent thermai conductivity.

Equation (2) may be integrated to obtain an expression for the heat flux as a function of radial position. The results of this integration are

$$
\begin{aligned}
& \text { - } K \frac{d T}{d r}=\frac{1}{2 \pi r}\left[Q_{0}-Q(r)\right] \text {, where } \\
& Q_{O}=-\left.2 \pi R_{O} K \frac{d T}{d r}\right|_{R_{O}}=\text { total linear heat generation, and } \\
& Q(r)=2 \pi \int_{r}^{R_{O}} q x d x=\begin{array}{l}
\text { linear heat generation between } r \\
\text { and } R_{0}
\end{array}
\end{aligned}
$$

The total linear heat generation, $Q_{0}$, is defined by the axial power distribution, and the linear heat generation, $Q(r)$, is defined in terms of the volumetric heat generation.

Equation (3) is integrated to obtain

$S(T)-S_{0}=\int_{T_{0}}^{T(r)} K d T=\frac{1}{2 \pi} \int_{r}^{R_{0}}\left[Q_{0}-Q(x)\right] \frac{d x}{x}$, where

$\mathrm{T}_{\mathrm{O}}=$ temperature at fuel surface, and

$\mathrm{S}_{\mathrm{O}}=$ Integrated fuel conductivity at the fuel surface.

The numerical calculations assume the heat generation and density of the fuel material to be constant in an annular ring. The resultant heat generation in the ring $r<x<R_{0}$, and the integrated thermal conductivity are 
BNWL -1241

$$
\begin{aligned}
& Q(x)=\pi q\left(R_{0}^{2}-x^{2}\right) \text {, and } \\
& S(r)=S_{0}+\frac{\pi R_{0}^{2} q}{4 \pi}\left\{1-\left(\frac{r}{R_{0}}\right)^{2}+\left[1-\frac{Q_{o}}{\pi R_{o}^{2} q}\right] \ln \left(\frac{r}{R_{0}}\right)^{2}\right\} .
\end{aligned}
$$

For an annular pellet of constant density, the constant volumetric heat generation $q$, is

$$
\begin{aligned}
& \pi R_{0}^{2} q=\frac{Q_{0}}{\left[1-\left(\frac{A_{0}}{R_{0}}\right)^{2}\right]}, \text { where } \\
& R_{0}=\text { outer radius } \\
& A_{0}=\text { inner radius }
\end{aligned}
$$

and the relation for the integrated thermal conductivity is

$$
S=S_{0}+\frac{Q_{0}}{4 \pi\left[1-\left(\frac{A_{0}}{R_{0}}\right)^{2}\right]}\left\{1-\left(\frac{r}{R_{0}}\right)^{2}+\left(\frac{A_{0}}{R_{0}}\right)^{2} \ln \left(\frac{r}{R_{0}}\right)^{2}\right\} .
$$

Equation (7) expresses the relation used to obtain the temperatures in the SINTER program. The values of $\mathrm{S}$ are calculated for the constant density ring and compared to the value $S$ given by Equation (1). A table inversion procedure is used to obtain the temperature value.

The first temperature calculated is the maximum temperature, $\mathrm{T}_{\max }$, in a fuel pellet not undergoing sintering. This temperature is used to determine whether center melting at start-up or sintering will occur. If sintering occurs, $\mathrm{T}_{\max }$ $>\mathrm{T}_{\mathrm{b}}$ - sintering temperature, Equation (7) can be solved for the sintering radius, $\mathrm{R}_{\mathrm{b}}$ : 
BNWL - 1241

$$
\left(\frac{R_{b}}{R_{0}}\right)^{2}-\left(\frac{A_{o}}{R_{o}}\right)^{2} \ln \left(\frac{R_{b}}{R_{0}}\right)^{2}=1-\frac{4 \pi\left[1-\left(\frac{A_{0}}{R_{o}}\right)^{2}\right]\left(S_{b}-S_{0}\right)}{Q_{0}}
$$

where $\mathrm{S}_{\mathrm{b}}$ = integrated thermal conductivity at $\mathrm{T}_{\mathrm{b}}$ for the unsintered density.

If the pellet is solid, then Equation (8) may be directly solved for $\mathrm{R}_{\mathrm{b}}$. A Newton approximation procedure is used to determine $\mathrm{R}_{\mathrm{b}}$ for an annular pellet.

When sintering occurs, the density, inner dimensions, and heat generation in the sintered regions are altered. Conservation of mass is used to calculate the new inner radius $A_{S}$ as follows:

$D_{u}\left(R_{b}^{2}-A_{O}^{2}\right)=D_{s}\left(R_{b}^{2}-A_{s}^{2}\right)$, where

$\mathrm{D}_{\mathrm{u}}=$ relative fraction of theoretical density unsintered.

$\mathrm{D}_{\mathrm{S}}=$ relative fraction of theoretical density sintered.

Equation (7) is used to determine the temperatures in the sintered region once the following substitutions are made:

$$
\begin{aligned}
& S_{0} \rightarrow S_{b}=S\left(T_{b}\right) \text { for } D_{S}, \\
& Q_{0} \rightarrow Q_{b}=Q_{0}-Q\left(R_{b}\right), \\
& R_{0} \rightarrow R_{b} \text { and } A_{o} \rightarrow A_{S} .
\end{aligned}
$$

\section{CALCULATIONAL PROCEDURE}

The calculational procedure for the temperatures within the fuel material is schematically presented in Figure 2 and is made with the subroutine SINTER listed in the Appendix. The input and output variables for this subroutine are given in this listing and the SPNTER program input is given in Table 1. The appropriate integrated thermal conductivity tables for the unsintered and sintered densities are developed 

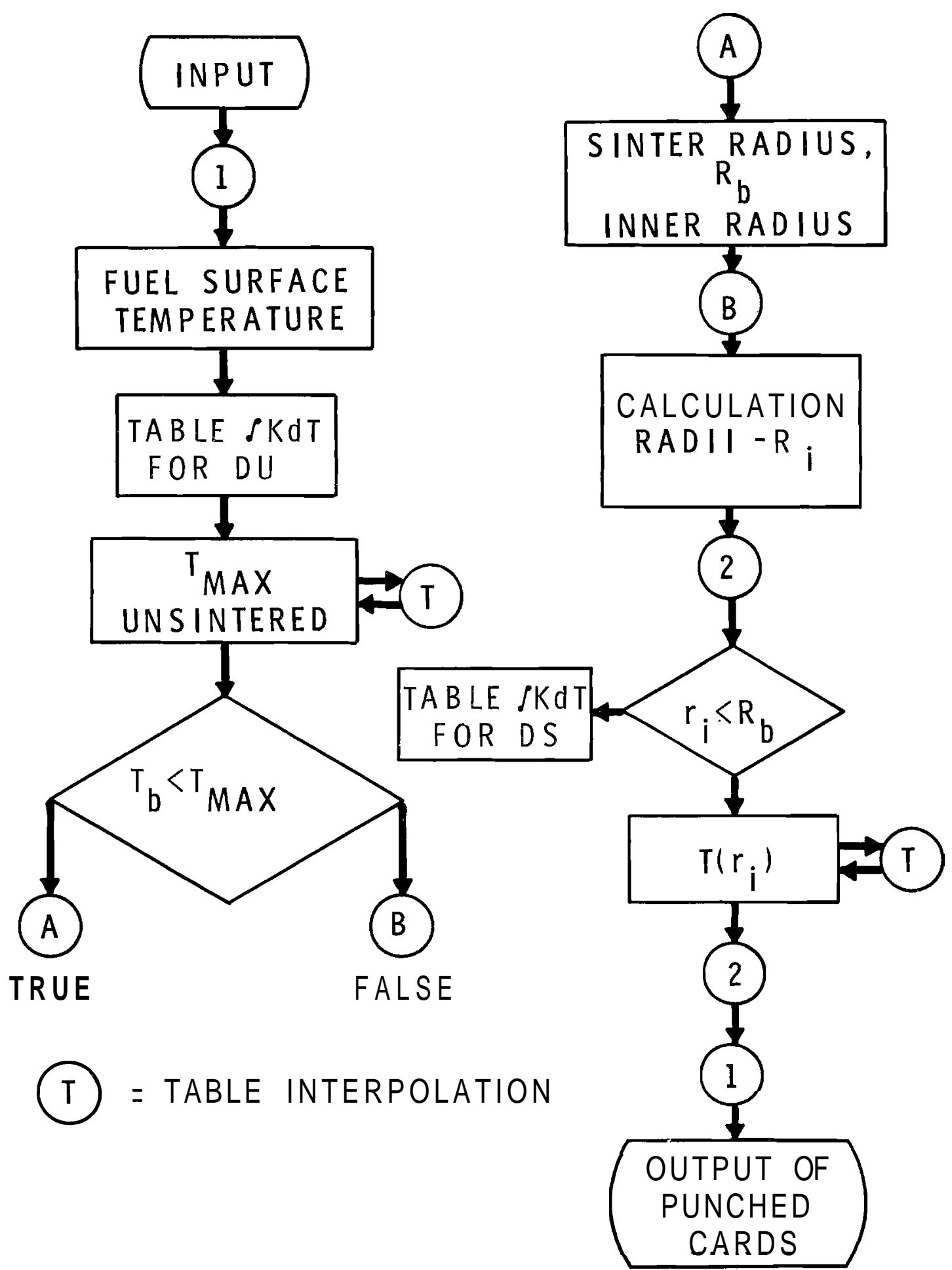

FIGURE 2. Calculational Steps for the SINTER Program 
BNWL - 1241

\section{TABLE 1. SINTER Program input}

Input Information

\begin{tabular}{|c|c|}
\hline FLEN & Fuel Fin Length, ft \\
\hline E & Extrapolation Distance, ft \\
\hline PM & Maximum Pin Heating Rate, $\mathrm{kw} / \mathrm{ft}$ \\
\hline $\mathrm{DP}$ & Pin Diameter, ft \\
\hline $\mathrm{CT}$ & Cladding Thickness, ft \\
\hline $\mathrm{CMF}$ & Coolant Mass Flow Kate, 1b/hr \\
\hline $\mathrm{CP}$ & Coolant Specific Heat, Btu/1b- ${ }^{\circ} \mathrm{F}$ \\
\hline $\mathrm{HF}$ & Film Coefficient, Btu/ft ${ }^{2}-{ }^{\circ} \mathrm{F}-\mathrm{hr}$ \\
\hline HG & Cap Coefficient, Btu/ft ${ }^{2}{ }^{\circ} \mathrm{F}-\mathrm{hr}$ \\
\hline $\mathrm{CK}$ & Cladding Conductivity, Btu/ft- ${ }^{\circ} \mathrm{F}-\mathrm{hr}$ \\
\hline $\mathrm{TI}$ & Inlet Coolant Temperature, ${ }^{\circ} \mathrm{F}$ \\
\hline $\mathrm{TB}$ & Temperature, ${ }^{\circ} \mathrm{F}$ \\
\hline DENLO & $\begin{array}{l}\text { Fraction Theoretical Density } \\
\text { Unsintered }\end{array}$ \\
\hline DENHI & $\begin{array}{l}\text { Fraction Theoretical Density } \\
\text { Sintered }\end{array}$ \\
\hline FD & Fuel Pellet Outer Diameter, ft \\
\hline FID & Fuel Pellet Inner Diameter, ft \\
\hline SEQUM & Number of Segnents \\
\hline
\end{tabular}

at each axial location case during the calculations for the radial temperature distribution. The calculations are repeated for each axial location as well as for fuel where the temperature distribution is desired. Various schemes for picking the desired radial locations for determining the temperature have been used such as locations based on equal volume or equal radial size increments throughout the fuel. region. The version listed in the Appendix is for equal size increments.

After the radial temperature distribution has been calculated, print and punch outputs are supplied to the user by the main program called SINTR. The actual SINTR program has many 
versions and is used to evaluate temperature dependent conditions within the fuel. material. Only the basic scheme for calculating the distribution of radial temperature in the fuel is described in this report.

Programs considering the densities of additional sintering regions can be developed by using the same principles. Since the calculations for each sintered region are based on the same relati-onships, the development of any number of sintered boundaries involves only an extension of the logic statements within the program. This procedure has been programmed for the HYBRID computer by using a three-region fuel pellet.

\section{SUMMARY AND CONCLUSIONS}

The SINTER program has found many applications for evaluating the temperatures within fuel materials. It takes into account the structural changes occurring during irradiation, and the temperature dependent conductivity of the fuel material. By utilizing the table-look-up procedures for a temperature integral of the conductivity, either tabular values or analytical approximations for this function may be used in the calculational procedure. The general procedure can be adapted for considering various irradiation effects on the thermal conductivity of the fuel materials. The direct hook-up of the SINTER program to other calculational procedures has made it a useful tool in evaluating irradiation behavior of reactor fuel materials. The actual adjustment of the parameters for the sintered density, and temperatures at which sintering occurs, is performed by the HYBRID computer. A version of this program is used to make correlations with the observations made on fuel materials irradiated under prototypical conditions. A three-region version of the SINTER subroutine is used in these correlations. 
BNWL - 1241

APPENDIX

RADIAL TEMPERATURE DISTRIBUTION CALCULATIONAL PROGRAM 
APPENDIX 1

RADIAL TEMPERATURE DISTRIBUTION CALCULATION PROGRAM

SUBROUTINE SINTER

SINTER SUBROUTINE

A SUBROUTINE TO CALCULATE THE RADIAL TEMPERATURE DISTRIBUTION IN AN ANNULAR PELLET ASSUMING SINTERING ABOVE TB AND TEMPERATURE DEPENDENT CONDUCTIVITY*

*** NOMENCLATURE

INPUT

TB = SINTERING TEMPERATURE - (F)

TO = SURFACE TEMPERATURE - (F)

RO = OUTER RADIUS

AO = INITAL INNER RADIUS

QO = LINEAR HEAT GENERATION - (BTU/(HR*FT))

DU = UNSINTERED FRACTION THEORETICAL DENSITY

DS = SINTERED FRACTION THEORETICAL DENSITY

NR = NUMBER OF REGION (NR+I=NUMBER OF TEMPERATURES) OUTPUT

TR = TEMPERATURES - (F)

TMAX = MAX TEMPERATURE WITHOUT SINTERING - (F)

RB = RADIUS OF SINTERED REGION

AS $\quad=$ FINAL INNER RADIUS

--ALL LENGTH MEASUREMENTS IN SAME UNITS - -

*\%*SUBROUTINE AND FUNCTIONS

YTON = NEWTON APPROXIMATION $Y-B * A L O G(Y)-C=0$

TABLE = CREATES VALUES IN TABLE OF T

$S \quad=$ CALCULATE INTEGRAL OF THERVAL CONDUCTIVITY-(BTU/(HR*FT))

$\mathrm{T} \quad=$ INTERPOLATS FOR TEMPERATURE - (F)

COMMON / SNTR / TB, TO, RO, AO, QO, DU, DS, NR,

1

DATA PI/3.141592/

C

$10 \mathrm{SO}=\mathrm{S}(\mathrm{TO}, \mathrm{DU})$

$A R 2=(A O / R O) * * 2$

$\mathrm{CU}=.25 * \mathrm{Q} O /(\mathrm{PI} *(1 .-\mathrm{AR} 2))$

C
C
C

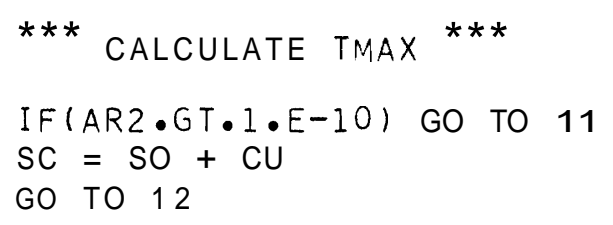


BNWL - 1241

11 CONTINUE

$S C=S O+C U *(1 \cdot-A R 2+A R 2 * A L O G(A R 2))$

12 CONTINUE

CALL TABLE(DU,TO)

TMAX $=T(S C)$

*** CALCULATE RB ****

IF (TMAX.LE.TB) RB=-1 •

IF (TMAX.LE•TB) GO TO 2 ?

$S B=S(T B, D U)$

$C K=1 .-(S B-S O) / C U$

IF (AR2 $\cdot G T \cdot I \cdot E-8)$ GO TO 15

$R R=R O * S Q R T(C K)$

GO TO 20

15 CONTINUE *

$R B=R O$ KQRT $(Y T O N(A R 2, C K)$,

20 CONTINUE

C

*** CALCLATE AS $* * *$

$A S=A O$

$I F(A O \cdot G T \cdot R B)$ GO TO 30

$S B=S(T B, D S)$

$A S=S Q R T(R B * 2-D U *(R B * 2-A O * * 2) / D S)$

$A S 2=(A S / R B) * 2$

$Q B=Q O *(1 .-(1 \cdot-R B * 2 / R O * * 2) /(1 \cdot-A R 2))$

$C S=.25 * Q B)(P I *(1 \cdot-A S 2))$

CONTINUF.

*** CALCULATE TEMPERATURE DISTRIBUTION ***

NCALL $=0$

$\mathrm{RR}=\mathrm{RO}$

$D E L R=(R O-A S) / F L O A T(N R)$

$T R(1)=T O$

DO $40 \quad I=1, N R$

$R R=R R-D F L R$

IF ( RR $\quad$ GF $\bullet R B)$ GO TO 35

IF(NCALL.EQ.0) CALL TABLE(DS,TB)

NCALL $=1$

$R C 2=(R R \quad / R B) * 2$

$S C=S B+C S *(1 .-R C 2+A S 2 * A L O G(R C 2))$

$T R(I+1)=T(S C)$

GO TO 40

35 CONT INUE

$R C 2=(R R \quad / R O) * * 2$

IF (RC2.GT.1.E-IO) GO TO 36

$\mathrm{SC}=\mathrm{SO}+\mathrm{CU}$

GO TO 37

36 CONTINUE

$S C=S U+C U *(1 .-R C 2+A R 2 * A L O G(R C 2))$

37 CONTINUE

$T R(I+I)=T(S C)$ 
40 CONTINUE

RETURN

END

SUBROUTINES

C
C
C

FUNCTION YTON(B,C)

MAKES NEWTON APPROXIMATION FOR $Y \rightarrow B^{*} A L O G(Y)-C=0$

$\mathrm{NCT}=0$

$Y A=C$

10 YTON $=(C-B *(1 .-A L O G(Y A)), /(1 .-B / Y A)$

TEST $=$ ABS ( YTON/YA - 1•)

$Y A=Y T O N$

$\mathrm{NCT}=\mathrm{NCT}+1$

IF (NCT.GT.IUO) GO TO 20

IF ( TEST.GT• 1.E-8) GO TO 10

RFTURN

20 WRITE $(6,25)$ TEST

25 FORMAT (43H FAILURE TO CONVERGE IN YTON (YTON/YA)-1=, E10.4) RETURN

END

FINNCTION $S(T, D)$

C
$C$
$C$
$C$
$C$
$C$

C CALCULATFS INTEGRAL (KDT)

C $T=$ TEMPERATURE $-F$

$D=$ FRACTION OF THEORETICAL DENSITY

$S=$ INTEGRAL FUNCTION - BTU/(HR*FT)

$S F(X)=X * .613 /(.09 \cup 84-. \cup 7306 * D)-(54.615 * D+167.173) * E X P(-.00154 * X)$

IF(T.GT.3272. $)$ GO TO 10

$S=S F(T)$

RFTLIRN

10 IF(T.GT.5432.) GO TO 20

$15 S=S F(3272 \bullet)+1.31769 *(T-3272 \bullet)$

RETURN

20 CONTINUE

WRITE $(6,25)$

25 FORMAT (39HMELTING OCCURED - CALCULATIONS IN ERROR )

GO TO 15

END

SUBROUTINE TABLE(D,T)

C

SUBROUTINE TO SET UP COEFFICIENTS IN A QUADRATIC TABLE

INTERPOLATION. VALUES ARE IN LABLED COMMON 


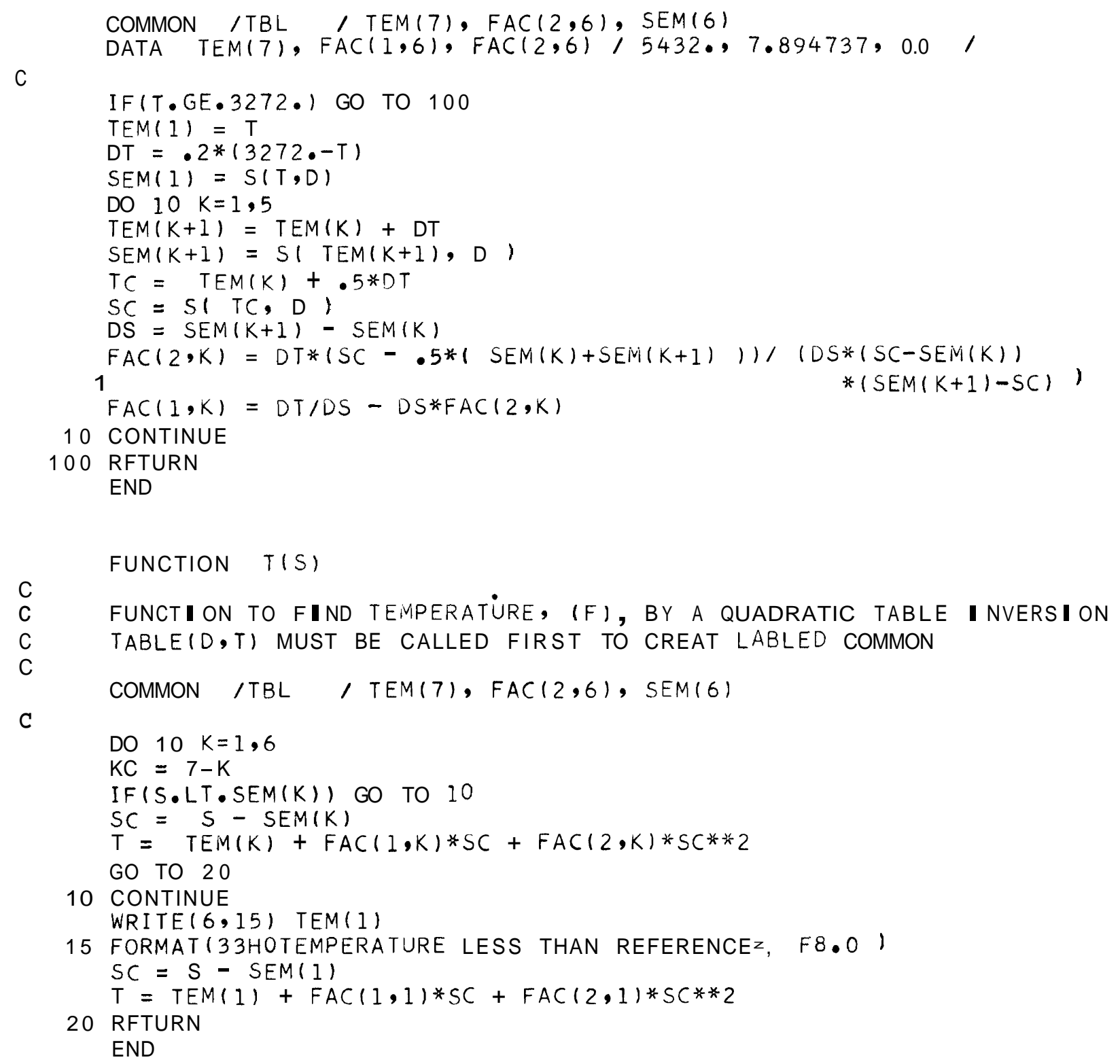




\section{DISTR IBUTION}

No. of

Copies

OFFSITE

AEC Chicago Patent Group

G. H. Lee

AEC Division of Reactor Development and Technology

M. Shaw, Director, RDT

Asst Dir for Nuclear Safety

Analysis \& Evaluation Br, RDT:NS

Environmental $\&$ Sanitary Engrg Br, RDT:NS

Research \& Development Br, RDT:NS

Asst Dir for Plant Engrg, RDT

Facilities $B r$, RDT: PE

Components $\mathrm{Br}$, RDT:Pg

Instrumentation $\varepsilon_{7}$ Control $\mathrm{Br}, \mathrm{RDT}: \mathrm{PE}$

Liquid Metai Systems Br, RDT:PE

Asst Dir for Program Analysis, RDT

Asst Dir for Project Mgnt, RDT

Liquid Metals Projects Br, RDT:PM

FFTF Project hanager, RDT:AM (3)

Asst Dir for Reactor ungrg, RDT

Control Mechanisns Br, RDT: RE

Core Design Fr, RDT:RE (2)

Fuel Engineering $B$, RUT:RE

Fuel Handling $\mathrm{BT}$, ROT:RE

Reactor Vesseis Br, RDI:RE

Asst I)ir for Reactor Tech, RDT

Coolant Chemistry Br, RDT:RT

Fuel Recycle Br, RDT:RT

Fuels $z$ Materials Br, RDT: RT

Reactor Physics Br, RDT:RE

Special Technology Br, KDT:RT

Asst Dir far Engrg Stsndards, RDT

EBR- TI Project Manager, RDT: PM

AEC Division of Technical information Extension

AEC Division of rechrical information Extension

US/UK Fast Reactor Exchange (12)

Eratom/US Fast Reactor Exchange (35)

1 AEC Idaho Operatiors Office

Nuclear Technology Division

C. W. Rills, Director 
No. of

Copies

1

4

3

1

7

2

10

1

1

$\frac{\text { Combustion Engineering }}{1000 \text { MWe Follow-On Study }}$

W. P. Staker, Project Manager

5

Director, Reactor Division

AEC Site Representatives

Argonne National Laboratory

Atomics International

General Electric Co.

Argonne National Laboratory

R. A. Jaross

LMFBR Program Office

N. J. Swanson

Atomic Power Development Assoc.

Document Librarian

Atomics International

FFTF Program office

Liquid Metal Information Center

A. E. Miller (2)

Babcock \& Wilcox Co.

Atomic Energy Division

S. H. Esleeck

G. B. Garton

Bechtel Corporation

BNW Representative

R. M. Fleischman (ZPPR)

General Electric Company
AEC San Francisco Operations Office

Atomic Power Development Assoc.

J. J. Teachnor, Project Administrator, FFTF

Advanced Products Operation

Karl Cohen (4)

Nuclear Systems Programs

D. H. Ahmann

Distr-2 
No. of

Copies

2

Gulf General Atomic Inc. General Atomic Division

\section{Coburn}

1

Idaho Nuclear Corporation

D. R. deBoisblanc

1

Stanford University

Nuclear Division

Division of Mechanical Engrg

R. Sher

1

United Nuclear Corporation

Research and Engineering center

R. F. DeAnge 1 is

15 Westinghouse Electric Corporation

Atomic Power Division

Advanced Reactor systems

J. C. R. Kelly

ONSITE - HANFORD

1

1

3

2

3

1

1
AEC Program Office - PNL

T. A. Nemzek

AEC Chicago Patent Group

R. K. Sharp

AEC RDT Site Representatives

P. G. Holsted

AEC Richland Operations Office

J. M. Shiviey

Battelle Memorial Institute

Bechtel Corporation

M. O. Rothwell (Richland)

Westinghouse Electric Corporation

R. Strzelecki (Richland) 
BNWL - 1241

No. of

Copies

76

Battelle-Northwest

E. R. Astley
E. O. Ballard
F. E. Bard
D. C. Bullington
J. C. Cochran
C. R. Cole
P. D. Cohn
D. L. Condotta
G. E. Culley
D. S. Duff
J. F. Erben
E. A. Evans
R. L. Fish
G. L. Fox (5)
F. C. Gronemeyer
J. E. Hanson
P. L. Hofmann
J. J. Holmes
R. L. Jackson
D. C. Kolesar
R. D. Leggett (5)
H. E. Little

W. E. McClung

W. B. McDonald

J. S. McMahon

K. R. Merckx (10)

M. K. Millhollen

A. Padilla

L. A. Pember

D. E. Peterson

W. E. Roake

D. O. Shepard

R. J. Squires

D. D. Stepnewski

V. B. Watwood, Jr.

J. W. Weber

C. L. Wheeler

D. R. Wilson

W. R. Wykoff

Legal - 703 Building

Legal - ROB, 221-A

Technical Information (5)

Technical Publications (2)

FFTF File, 703 Bldg. (10)

FFTE TPO (List "T") 